\title{
Tradição e modernidade na família oitocentista ${ }^{12}$
}

Carlos Eduardo Nicolette*

As dissertações e teses acerca da história da família brasileira têm crescido em número considerável nas últimas duas décadas, não apenas pela criação dos programas de pósgraduação nas Universidades brasileiras, mas também pela ampliação do acesso à documentação. Os temas abordados, também em muito têm variado e as máximas históricas existentes sobre o passado colonial e imperial têm sido reexaminadas, tanto na área da História Social quanto da História Econômica. Em seu livro As Memórias da Viscondessa: Família e Poder no Brasil Império, a historiadora Mariana Muaze se debruça sobre uma família oitocentista brasileira, procurando compreender as transformações e adequações ocorridas dentro do seio dessa esfera social no século XIX. A autora procura, também, mostrar as temporalidades dessa família, mostrando, assim, mais do que seu espaço de sociabilidade, mas também o espaço privado e de que forma as relações intrafamiliares foram importantes em suas modificações e, principalmente, permanências ao longo do século XIX.

A divisão do livro em três partes, a saber, A Força da tradição (1), Vida Material e Manutenção da Riqueza Familiar (2) e Múltiplas Temporalidades em Família (3), não se deu por acaso. A obra tem em seu início uma carga de genealogia, que parte do início do século XIX, ou seja, da formação das famílias senhoriais no Vale do Paraíba Fluminense. A segunda parte relata um período de manutenção do poderio adquirido por tais famílias com o café e as estratégias da própria classe senhorial para a permanência entre as famílias mais proeminentes do Império. A terceira apresenta, através dos retratos dos Ribeiro de Avellar, a

1MUAZE, Mariana de Aguiar Ferreira. As Memórias da Viscondessa: família e poder no Brasil Império. Rio de Janeiro: Zahar, 2008.

2Agradeço aos membros da Revista Epígrafe e as(os) pareceristas, seus comentários e contribuições promoveram as maiores virtudes desta resenha.

\footnotetext{
* Mestrando em História Social pela Faculdade de Filosofia, Letras e Ciências Humanas da Universidade de São Paulo, sob a orientação do Prof. Dr. Carlos de Almeida Prado Bacellar. Integrante do Centro de Estudos de Demografia Histórica da América Latina (CEDHAL). Contato: carlos.nicollete@usp.br
} 


\section{artigos}

Carlos Eduardo Nicolette

vida da família oitocentista e suas transformações no final do Império, derivadas, principalmente, das mudanças que ocorriam velozmente na Europa.

Sua pesquisa também ressalta parte dos arranjos sociais e políticos envolvendo o casamento de Mariana Velho da Silva e Joaquim Ribeiro de Avellar Jr. As famílias de ambos tinham condições bastante distintas: enquanto a dela se consolidara próxima à Coroa portuguesa pela troca de favores e contribuições ao Estado, a dele se alicerçava na riqueza proveniente da terra e do trabalho escravo através da plantação de café. Muaze destaca em seu livro a figura fundamental para a união dessas famílias distantes: o comissário Domingos Alves da Silva Porto. Este, trabalhava para negociar o café dos Avellar no Rio de Janeiro e também para cuidar da educação de Avellar Jr. Foi Domingos que possibilitou a aproximação entre tão diferentes famílias, se utilizando de seu conhecimento da economia moral do dom oitocentista brasileiro e da compreensão dos interesses dos sujeitos envolvidos, principalmente da busca por prestígio social advindo dos Avellar.

A fim de investigar, então, a condição das famílias oitocentistas, a historiadora lança mão de ampla documentação localizada em acervos pessoais referentes ao principal entroncamento familiar com a qual ela lida, os Ribeiro de Avellar. A organização de grande parte da documentação usada por Muaze é derivada de epístolas e fotografias guardadas por Mariana Velho de Avellar, que se tornaria Viscondessa de Ubá, em 1887, e de cartas de seu sogro, Joaquim Ribeiro de Avellar, feito Barão de Capivary em 1846. A partir dessa família, a autora articula uma série de outras documentações para reconstruir seu habitus ${ }^{3}$, ou seja, compreender as formas de agir dentro do seio familiar das mais altas esferas sociais dessa elite. Cabe, aqui, uma contrapartida à reflexão da autora. Ela não especifica de qual família oitocentista se trata. Seria daquelas mais próximas da província do Rio de Janeiro, das estritamente donas de cafezais ou mesmo das que fazem parte da elite financeira do Império do Brasil? E se a autora se refere à família patriarcal, onde estão os escravos em sua análise?

3 Para aprofundamento do conceito de habitus, ver ELIAS (1984, p. 90). Para outra discussão sobre a classe senhorial escravista do Vale do Paraíba, ver SALLES (2008). 


\section{artigos}

Tradição e modernidade na família oitocentista

Caso se refira à família extensa, onde aparecem as outras convivências com livres e libertos na fazenda Pau Grande? Nessa reinvenção da família que Muaze defende ao longo de seu livro, como ficam aqueles que não estão no núcleo familiar? Não fica claro, portanto, se a partir de seu exercício de micro-história, ela indica um panorama geral das famílias da elite brasileira na modernidade ou apenas da elite fluminense.

Mesmo com a falta de precisão sobre qual tipo de família a autora se refere, ela defende que as mudanças ocorridas no final do século XIX na Europa - derivadas do pensamento burguês e iluminista, seja na individualidade das ações, na procura pelo amor romântico ou na valorização da infância como crucial fase da vida - refletiram diretamente na classe senhorial, que buscou sintonizar-se com o contexto cultural europeu. Muaze nos mostra essa família oitocentista sempre na busca pelo fortalecimento próprio perante às outras, numa disputa velada para ver qual era mais sofisticada e refinada - seja com viagens para a Europa, cartes de visite assinadas por famosos fotógrafos, roupas sempre de acordo com a moda ou até com as relações próximas à família Imperial.

Procurando compreender a formação da elite cafeeira do Vale do Paraíba, Muaze utiliza como arcabouço teórico as afirmações dos renomados historiadores João Luis Ribeiro Fragoso e Manolo Florentino ${ }^{4}$. Ela inicia sua reflexão a partir da conclusão destes autores, discutindo que, durante o primeiro quartel do século $X I X$, o movimento de investimento dos comerciantes atuantes na zona do Vale do Paraíba foi impulsionado por um ideal arcaico que era perpassado pelo ethos senhorial. Nas palavras de Fragoso, "as relações de poder assumiam o papel de relações de produção e a mobilidade social significava tornar-se senhor de homens" (FRAGOSO, 1998, p. 36).

Para a autora, o movimento de busca pelo prestígio e ascensão social por parte dos comerciantes de grosso trato do Rio de Janeiro, aconteceria mesmo se precisassem, para isso, perder dinheiro, pois investir em terras e escravos era sinal decisivo da tão desejada distinção

4 Muaze utiliza uma série de referências de Fragoso para argumentar sobre o conceito de arcaísmo. Ver FRAGOSO (1998) e FRAGOSO; FLORENTINO (2011). 


\section{artigos}

Carlos Eduardo Nicolette

social. Ao longo de seu texto, Muaze volta, várias vezes, a dialogar com as teses de Fragoso, argumentando que a mentalidade operante entre as famílias oitocentistas também se alterou dentro do próprio arcaísmo, dado que, na passagem da primeira para a segunda metade do XIX, não bastava mais tornar-se senhor de escravos e dono de terras, mas impunha-se também a necessidade de se obter títulos de nobreza.

É dessa forma, dialogando diretamente com Fragoso, que a historiadora procura situar a formação das plantations cafeeiro-escravistas do Vale do Paraíba, concordando que os comerciantes de grosso trato e outros sujeitos teriam agido com base em um pensamento arcaico. Rafael de Bivar Marquese, autor de vasta bibliografia acerca do escravismo no século XIX a partir do conceito de Segunda Escravidão ${ }^{5}$, debate sobre a expansão do sistema escravista e cafeeiro no Brasil após 1815 e a formação do Vale do Paraíba. Para o autor, tal expansão foi resultado tanto de transformações econômicas, ligadas ao mercado mundial dos produtos coloniais, à crescente demanda por café nos países industrializados e em processo de industrialização e à queda da produção mundial após a revolta de São Domingos, quanto de políticas, ligadas à abertura dos portos, à independência brasileira e às "permissões" feitas à escravidão no Brasil, mesmo após a proibição do comércio de escravos (MARQUESE; TOMICH, 2010, pp. 341-383).

Rafael Marquese e Dale Tomich afirmam que a expansão da cafeicultura no centro-sul do país, a partir de 1820, só foi possível graças à conjuntura que reuniu as melhores condições do mercado mundial e a situação interna do Brasil, que levou à continuidade da escravidão e do tráfico negreiro e consequentemente ao aumento da produção agrícola. Foi por tal conjuntura da terceira década do século XIX, afirmam os autores, que grandes

\footnotetext{
5“Em um ensaio pioneiro publicado originalmente há vinte anos, Dale Tomich propôs a categoria 'segunda escravidão', para apreender em um quadro conjunto a novidade da escravidão atlântica oitocentista. De acordo com seu argumento, as modificações ocorridas com o advento da economia-mundo industrial do século XIX impuseram aos senhores de escravos americanos a necessidade do aumento constante da produtividade de seus cativos, sob o risco de se verem excluídos do mercado mundial. (...) Em cada uma dessas novas fronteiras da mercadoria surgiram unidades produtivas escravistas com plantas inéditas, cujas combinações de terra, trabalho e capital romperam com os padrões anteriormente vigentes no mundo atlântico" (MARQUESE, 2010, p. 83-84).
} 


\section{artigos}

Tradição e modernidade na família oitocentista

propriedades cafeicultoras foram criadas no Vale do Paraíba em um pequeno espaço de tempo. Com elas, o Brasil se tornou o maior produtor de café do mundo. A produção brasileira do fruto saltou de 13,5 mil toneladas, em 1821, para 67 mil toneladas, em 1833, montante equivalente à produção mundial no ano de 1790 (MARQUESE; TOMICH, 2010, p. 355).

Em relação à formação e expansão das plantations escravistas no Vale do Paraíba, Marquese afirma que "pela própria natureza do objeto em questão, desconsiderar o mercado mundial como uma dimensão central de sua formação conduz a uma compreensão reduzida e, portanto, incompleta do fenômeno estudado" (MARQUESE, 2013, p. 251). Mariana Muaze, inclusive, modificou sua base teórica quanto à formação do Vale do Paraíba após o livro As Memórias da Viscondessa. Em seu artigo posterior à publicação do livro, intitulado O Vale do Paraíba Fluminense e a dinâmica imperial (2010), a autora não utiliza mais como arcabouço teórico as teses de Fragoso e Florentino; ao invés disso, procura relacionar a formação do Vale do Paraíba Fluminense às teses relativas à Segunda Escravidão, com textos de Rafael Marquese e Dale Tomich.

Mariana Muaze traz diversos autores para a discussão em seu livro. Primeiramente, Gilberto Freyre e seu conceito de família, que ela concorda ser o grande fator colonizador do Brasil, sendo a família uma unidade política, colonizadora e produtiva, na qual os casamentos têm crucial função para a manutenção e aumento das riquezas (MUAZE, 2008, p. 45). Assim, a autora reitera a função arcaica dos casamentos e a convergência de troncos familiares distintos como reprodução da "dinâmica hierarquizante fundadora da composição do Império" (MUAZE, 2008, p. 55).

Para a discussão do amplo acervo fotográfico que utiliza em seu livro, a autora tem como suporte teórico principal as formulações da historiadora Ana Maria Mauad (1996), a qual entende fotografia como uma forma privilegiada de representação da sociedade oitocentista. Representação esta que foi arquitetada a partir das famílias mais abastadas 


\section{artigos}

Carlos Eduardo Nicolette

daquela sociedade e caracterizada pela busca incessante de formas de prestígio social, encontrado, então, na reformulação das práticas burgueso-europeias de fins do XIX, na manutenção do poderio econômico e na aquisição de títulos nobiliárquicos.

A autora também dialoga com o sociólogo Norbert Elias, mostrando que, em seu trabalho A Sociedade de Corte (1995), a autorrepresentação dos grupos e indivíduos está intimamente ligada ao fato de serem sociedades altamente hierarquizadas. Partindo dessa base, Muaze afirma que a sociedade por ela estudada se encaixa nesses padrões, ou seja, que essa elite procura a todo momento se autorrepresentar. Nas palavras da autora "as categorias do "ser" e do "parecer" tendiam a se identificar, cada vez mais, reforçando a hierarquia constituída ou contribuindo para subvertê-la" (MUAZE, 2008, p. 53).

Existe um problema quanto ao silêncio da relação entre essa elite e os escravizados em As Memórias da Viscondessa, pois, segundo Muaze, o habitus senhorial se transformou durante o século o XIX, justamente por que essa classe obteve um vasto poderio econômico e adquiriu expressiva influência europeia - vestimentas, individualidade, amor romântico etc. -, mas todas essas influências só foram possíveis por meio da brutal exploração e do controle da mão de obra escrava, visto que foi por meio desta que se deu o enriquecimento desses senhores, sobretudo no que se refere às elites do Vale do Paraíba. Entretanto, a documentação utilizada por Muaze é marcada pelo ocultamento das relações escravistas, o que permite evidenciar as intenções senhoriais, mas decerto não demonstra a realidade vivida por aquelas famílias, as quais tinham o vínculo escravista subentendido em cada momento do seu dia: nas refeições, nos negócios e, no caso das famílias que viviam diretamente nas fazendas de café, no seu quintal - o seio da produção e da exploração, logo, de sua riqueza.

A própria autora não se coloca criticamente perante essas relações, as mesmas que não podem ser esquecidas ao tratar das famílias senhoriais, mesmo que essas prezassem pelo refinamento em suas relações, procurando ocultar ao máximo a brutalidade da escravidão do 


\section{artigos}

Tradição e modernidade na família oitocentista

Oitocentos. Cabe o questionamento à autora se os mais de 700 escravizados do Barão de Capivary, em $1863^{6}$, não teriam sido personagens históricos ativos na construção do poder dessa família oitocentista. A historiadora contou o silêncio de suas fontes, nos mostrou apenas as omissões da viscondessa. Entretanto, este mesmo silêncio sobre a escravidão poderia ter contribuído, e muito, na compreensão daquela realidade familiar senhorial.

Isto posto, a obra de Muaze buscou compreender as estratégias aplicadas pelas famílias oitocentistas para subir aos patamares mais dignos daquela sociedade que, para a autora, são o prestígio social advindo de terras, a aquisição de títulos nobiliárquicos - num sistema arcaico de sociedade - e, posteriormente, agregação de valores europeizados - liderados pela ascensão da individualidade. Ela conclui As Memórias da Viscondessa refletindo sobre as temporalidades da vida familiar para a elite do Oitocentos, utilizando, para isso, os retratos daqueles sujeitos e as transformações significativas neles presentes, evidenciadas pelas poses, vestimentas, configurações do cenário fotografado e, especialmente, pelo endereçamento dos cartes de visite, muito utilizados devido ao pequeno tamanho e o baixo custo, facilitando a distribuição e circulação entre a elite.

Por fim, apesar da problemática envolvendo a formação do complexo agrícola do Vale do Paraíba Fluminense e do silêncio perante as relações escravistas, Mariana Muaze nos apresenta uma interessante reflexão acerca da adoção e da ressignificação das práticas burgueso-europeias pela família Ribeiro Avellar. Também se mostra louvável e frutífero seu esforço na busca pela compreensão das estratégias familiares no contexto da economia cafeeiro-escravista do século XIX. A autora identifica e qualifica os métodos pelos quais a família oitocentista se reinventou e reordenou seu habitus, sendo o entroncamento criado a partir do casamento entre Joaquim Ribeiro de Avellar Jr. e Mariana Velho da Silva no ano de 1849 o principal o foco de Muaze. Essa família se apresenta e representa como um exemplo que buscou, em laços familiares e políticos, ascensão social e privilégios político-econômicos no Brasil Imperial.

6 Sendo 213 escravizados apenas na fazenda Pau Grande, residência principal da família Ribeiro de Avellar. 


\section{artigos}

Carlos Eduardo Nicolette

\section{REFERÊNCIAS BIBLIOGRÁFICAS}

ELIAS, Norbert (1984). A Sociedade de Corte. 2a ed. Lisboa: Estampa, Mi Trayectoria Intelectual. Barcelona: Ediciones Península, 1995.

O Processo Civilizador: Uma história dos costumes. São Paulo: Jorge Zahar, volume I, 1998.

FRAGOSO, João Luis. Homens de grossa aventura: acumulação e hierarquia na praça mercantil do Rio de Janeiro (1790-1830). Rio de Janeiro: Civilização Brasileira, $2^{a}$ edição.

; FLORENTINO, Manolo. O arcaísmo como projeto: Mercado atlântico, sociedade agrária e elite mercantil em uma economia colonial tardia (1790-1840). Rio de Janeiro: Civilização Brasileira, 2001 (1ª edição 1993, edição revista).

MARQUESE, Rafael de Bivar. Feitores do corpo, missionário da mente: Senhores, letrados e o controle dos escravos nas Américas, 1660-1860. São Paulo: Companhia das Letras, 2004.

O Vale do Paraíba cafeeiro e o regime visual da segunda escravidão: o caso da fazenda Resgate. Anais do Museu Paulista, São Paulo, vol. 18, n. 1, jan./jul. 2010, p. 83-128.

As desventuras de um conceito: capitalismo histórico e a historiografia sobre a escravidão brasileira. São Paulo: Revista de História, n. ${ }^{\circ}$ 169, p. 223-253, julhodezembro, 2013. Disponível em: https://www.revistas.usp.br/revhistoria/article/ download/69188/71640. Acesso em: 27/09/2017. 


\section{artigos}

Tradição e modernidade na família oitocentista ; TOMICH, Dale. O Vale do Paraíba escravista e a formação do mercado mundial do café no século XIX in: SALLES, Ricardo; GRINBERG, Keila (org). O Brasil Imperial. Rio de Janeiro: Civilização Brasileira, 2010.

MAUAD, Ana Maria. Através da imagem: fotografia e história - Interfaces. Revista Tempo, Rio de Janeiro, vol. 1, $\mathrm{n} \stackrel{\circ}{\circ}$ 2, 1996, p. 73-98. Disponível em: http://xa.yimg.com/kq/groups/20486128/1000117760/name/Mauad+Fotografia+e+His t\%2B\%C2\%A6ria.pdf . Acesso em: 22/09/2017.

MUAZE, Mariana de Aguiar Ferreira. O Vale do Paraíba e a dinâmica Imperial. In: Inventário das Fazendas do Vale do Paraíba Fluminense - fase III. Rio de Janeiro: INEPACI Instituto Cidade Viva, 2010, v.3, p. 293-340. Disponível em: http://www.instituto cidadeviva.org.br/inventarios/sistema/wpzontent/uploads/2010/12/15_mariana_muaze.p df.Acesso em: 15/09/2017.

SALLES, Ricardo. E o Vale era o escravo: Vassouras, século XIX. Senhores e escravos no coração do Império. Rio de Janeiro: Civilização Brasileira, 2008 